\title{
AS CRÍTICAS DE HEGEL À TEORIA MORAL DE KANT: UM DEBATE A PARTIR D0 §135 DE LINHAS FUNDAMENTAIS DA FILOSOFIA DO DIREITO
}

\author{
Joel Thiago Klein \\ Universidade Federal de Santa Catarina
}

\begin{abstract}
The objective of this text is to explain the debate about Hegel's critic to Kant's moral theory just as it is formulated in $\S 135$ of Elements of the Philosophy of Right. Different interpretations regarding the critic to the vacuity of the categorical imperative and the possible Kantian answers are showed. Developing the points related to this critic, it is sustained that it is not only a punctual dispute that can be read independently of a systematic panorama. This text will defend that the debate is a consequence of different systematic presuppositions
\end{abstract} KEYWORDS: Hegel, Kant, categorical imperative, vacuity.

RESUMO: 0 objetivo deste texto é expor o debate sobre a crítica de Hegel à teoria moral de Kant tal como se encontra formulada no $\S 135$ de Linhas fundamentais da filosofia do direito. Apresenta-se diferentes interpretações a respeito da crítica à vacuidade do imperativo categórico e as possíveis respostas kantianas. Ao se desdobrar as questões subjacentes à crítica, sustenta-se que não se trata de uma disputa pontual, que possa ser lida independentemente de um panorama sistemático. Defende-se que esse debate é uma consequência de pressupostos sistemáticos distintos.

PALAVRAS-CHAVE: Hegel, Kant, imperativo categórico, vacuidade.

O debate que envolve as críticas de Hegel à teoria moral kantiana foi algo que por muito tempo não obteve o cuidado merecido. De acordo com Wildt, houveram, por um lado, autores marxistas como Marcuse, Lukács, Bloch e Adorno, os quais tenderam a desconsiderar o aspecto positivo que a crítica de Hegel à moralidade assume dentro da própria obra hegeliana, ou seja, a moralidade como sendo algo a ser superado, mas também incorporado 
na eticidade ${ }^{1}$. Por outro lado, autores como Mill, Dewey, Bergson e Brentano simplesmente se apropriaram da tese de Hegel sobre a vacuidade do imperativo categórico, sem perceber que se trata de uma crítica frustrada, pelo menos na formulação que por eles é apropriada ${ }^{2}$.

Todavia, mesmo sobre a relação entre a teoria moral kantiana e a eticidade hegeliana encontram-se posições bastante contrastantes. Ritter (1966), por exemplo, antagoniza a proposta kantiana e a proposta hegeliana, falando que a primeira, ao separar a moral do direito, acaba restringindo a moral ao âmbito interno onde apenas a boa vontade interessa, independentemente da questão da sua realização. Já a eticidade hegeliana procuraria superar a separação kantiana entre moral e direito, entre doutrina da virtude e doutrina do direito, por meio de um retorno à vinculação aristotélica entre ética e política, união que cunha o conceito hegeliano de eticidade. Knox (1957), por outro lado, acentua a proximidade de Hegel a Kant. Segundo ele, da mesma forma que Hegel se disse luterano, também deveria ter se declarado abertamente como um kantiano. E o fato de Hegel não ter desenvolvido uma teoria ética ao longo de sua vida se deve ao fato de ter estado fundamentalente em acordo com Kant e de não ter tido muito a acrescentar $^{3}$. Nesse sentido, as críticas de Hegel diriam respeito à insuficiência da moralidade enquanto tal e não à perspectiva kantiana da moralidade e que, finalmente, a "eticidade" hegeliana, assim como o "reino dos fins” em Kant, permanecem um ideal com fundamento religioso ${ }^{4}$.

Ora, já se percebe que o debate em torno da crítica de Hegel à Kant possui inúmeras facetas, sendo ao mesmo tempo instigante e difícil. A partir de 1980, com a intensificação dos estudos da filosofia kantiana, houve também uma retomada desse tema e, com isso, a produção de uma grande quantidade de material bibliográfico. De um lado, kantianos que procuram mostrar a não pertinência das críticas de Hegel, de outro, hegelianos que tentam reelaborar os argumentos mostrando aspectos mais profundos do que aqueles literalmente encontrados.

Neste trabalho se reconstrói especificamente o debate em torno das críticas de Hegel à teoria moral de Kant tal como são apresentadas no §135 de Linhas fundamentais da filosofia do direito. Num primeiro momento

\footnotetext{
${ }^{1}$ Cf. Wild, 1982, p. 27-35.

2 Cf. Wild, 1982, p. 57.

${ }^{3}$ Cf. KNOX, 1957, p. 70.

${ }^{4}$ Cf. KNOX, 1957, p.81.
} 
apresenta-se as críticas de Hegel, em seguida, as possíveis respostas de Kant, tal como colocadas pelos kantianos. Então, retoma-se novamente as críticas de Hegel, tal como reformuladas pelos hegelianos para, na sequência, tentar uma nova resposta kantiana. Finalmente, faz-se uma ponderação geral a cerca dos argumentos,mas sem a pretenção de solucionar o problema. Esse texto pretende mostrar como o debate em torno das críticas hegelianas ao imperativo categórico não pode ser resolvido de forma fragmentada, mas que depende de uma ponderação complexa a cerca de perspectivas sistemáticas distintas.

\section{Críticas de Hegel à teoria moral kantiana: apresentação do §135}

Segundo a terminologia hegeliana, a moralidade consegue apresentar um conceito de dever que alcança unicamente uma universalidade abstrata (abstrakte Allgemenheit) que traz em si apenas uma identidade sem conteúdo e que, por isso, não passa de uma mera identidade sem conteúdo (inhaltslose Identität). Ainda que a filosofia kantiana tenha pela primeira vez trazido à tona as raízes do conceito de dever e fixado o conceito de autonomia, segundo Hegel, essa teoria não se sustenta, pois a partir dela não é possível nenhuma doutrina imanente do dever. Que isso significa? Que a doutrina kantiana pode ter fixado certos conceitos importantes, mas que ela fracassa no seu empreendimento de oferecer um critério seguro para o agir moral e para uma doutrina dos deveres. Trata-se da tese hegeliana da vacuidade do imperativo categórico. Segundo Hegel,

Se pode, a partir de fora, trazer uma matéria e por meio disso chegar a deveres particulares, mas a partir daquela determinação do dever - enquanto falta de contradição, à concordância formal consigo mesma, a qual não é nada mais do que a fixação da indeterminação abstrata, não se pode passar à determinação de deveres particulares, nem mesmo chegar à consideração de um conteúdo particular para o agir encontra-se um critério naquele princípio, se ele é um dever ou não. Ao contrário, todas as formas de agir, ilegais e imorais, podem ser legitimadas dessa forma. - A seguinte forma kantiana de se representar a capacidade de agir através de uma máxima universal provoca, na verdade, a representação concreta de um estado, mas não envolve por si nenhum princípio adicional além daquele da falta de 
contradição e da identidade formal. (Hegel: 1986, §135, tradução própria).

Com base nessa passagem, pode-se dizer que Hegel sustenta sua posição a partir das seguintes premissas:

a. O imperativo categórico kantiano não possui um conteúdo próprio, ele é apenas o princípio de não-contradição aplicado ao âmbito prático. Logo, não se pode derivar unicamente a partir dele um conceito determinado de dever.

b. O imperativo categórico só funciona como um princípio de universalização quando já existe a suposição de um conteúdo externo, mas, nesse caso, dependendo do conteúdo que é abarcado, pode-se derivar inclusive ilegalidades e imoralidades.

Ambas as premissas estão vinculadas na argumentação de Hegel, mas elas podem funcionar separadamente, isto é, ainda que o imperativo categórico não fosse um princípio meramente formal, poder-se-ia criticá-lo unicamente com base na segunda premissa. Neste caso, dir-se-ia que ele só funciona com a pressuposição de conteúdos, que por serem empíricos ou por serem às vezes ilegítimos poderiam causar imoralidades e ilegalidades. Hegel nos apresenta um exemplo sobre como ele pensa exatamente esses conteúdos:

Que não haja propriedade contém por si tão pouca contradição quanto que este ou aquele povo singular, família e assim por diante, não exista ou que em geral nenhum ser humano viva. Se, caso contrário, encontra-se fixado e pressuposto por si mesmo que a propriedade e a vida humana existem e devem ser respeitadas, então é uma contradição cometer roubo e assassinato. Uma contradição só pode resultar frente a algo que é, com um conteúdo, aquilo que como princípio anteriormente encontrava-se no fundamento. É em relação a um tal princípio que uma ação se encontra em concordância ou em contradição. (Hegel: 1986, §135, tradução própria) 


\section{Uma resposta kantiana}

Acredito que Kant defenderia as seguintes teses frente às críticas de Hegel:

a. O imperativo categórico não é um princípio meramente formal no sentido lógico, isto é, não se trata simplesmente de uma versão do princípio de não-contradição aplicado ao campo da filosofia prática;

b. A pressuposição de certos conteúdos empíricos não compromete a aplicação e a validade do imperativo categórico, ou seja, as conclusões do imperativo categórico não estão baseadas num círculo vicioso, no qual o que é concluído já se encontrava previamente suposto.

\subsection{0 imperativo categórico como um princípio transcendental}

Um dos pontos sobre os quais Kant mais despendeu cuidado no desenvolvimento de sua filosofia foi no estabelecimento da distinção entre o âmbito daquilo que pertence meramente à lógica geral e aquilo que se tornou objeto de seu estudo, o que ele chamou de lógica transcendental. Muitas vezes, mas não sem ter discorrido sobre o tema alhures, Kant fala que o imperativo categórico é um princípio formal e não material. Quando ele utiliza essa terminologia ele está pensando na propriedade segundo a qual o imperativo categórico pode ser aplicado como uma regra universal que, por não se originar da empiria, possui a capacidade de ser aplicado universalmente, para todos os seres racionais em geral e em todas as circunstâncias que envolvam a valoração de questões morais. $O$ ponto central que deve ser percebido é que o fato de o imperativo categórico ser formal não implica na falta de conteúdo. A filosofia transcendental de Kant, seja teórica ou prática, tem como objetivo justamente explicitar esse conteúdo que não advém da experiência e que por isso, em certo sentido, é formal, mas não a ponto de não possuir significado, ou seja, não a ponto de não servir como regra para julgar objetivamente a respeito do conteúdo de casos empíricos concretos. Dito de outra forma, a lógica geral trabalha com regras que podem ser empregadas indiscriminadamente a qualquer conteúdo, mas, por isso, não podem servir como critério de verdade ou como critério de ação, no caso da filosofia prática, já a lógica transcendental, tanto a teórica quanto a prática, 
tem a pretensão de explicitar certas estruturas que determinam a priori, seja o nosso modo de conhecer as coisas, seja o nosso modo de julgar o valor moral de uma norma. Em suma, pode-se dizer que todo o esforço da filosofia transcendental se dirige na tentativa de legitimar a existência de estruturas transcendentais teóricas e práticas. O conceito de "transcendental" envolve um conceito de "formal" que possui conteúdo e que por sua vez é distinto do conceito de "formal" que é utilizado pela lógica formal 5 .

Posto isso, seria estranho pensar que teria passado despercebido por Kant a utilização de um princípio lógico, como é o caso do princípio de nãocontradição, para servir de base de sua filosofia prática. Isso não aconteceu. Kant sabia muito bem dos limites do princípio de não-contradição, mais do que isso, foi justamente ele quem fez frente à filosofia leibniziana e wolffiana que pretendia deduzir a partir deste princípio verdades a respeito do mundo ${ }^{6}$.

Nesse sentido, quando Kant fala que uma determinada máxima, como aquela do furto, não pode ser universalizada, pois ela gera uma contradição, com certeza ele não está falando de uma contradição lógica. Em outras palavras, não se trata da possibilidade de conseguir pensar um mundo onde todos tenham essa máxima. Também não é o problema conseguir pensar em um mundo sem propriedade ou mesmo em um mundo que não tenha vida humana, assim como Hegel afirmou. O ponto da argumentação de Kant é o de que não se consegue querer que a máxima do furto seja universalizada. A tese é que o imperativo categórico funciona como um teste de universalização de máximas de forma que, por meio dele, consegue-se identificar as máximas que se pode racionalmente querer que sejam universalizadas 7 . O imperativo categórico indica ou não a existência de uma contradição interna à vontade do agente, na medida em que ele se pensa ao mesmo tempo como um agente sensível e um ser racional.

Segundo Kant, o imperativo categórico possui um conteúdo prático a priori, pois ele é a expressão da lei universal, que no caso de agentes sensíveis se torna um mandamento, um imperativo. Nesse sentido, o imperativo não

\footnotetext{
${ }^{5}$ Cf. Kant KrV, AA 03: 42-48; 74-78/ B24-30; 74-88. As obras de Kant serão citadas de acordo com a paginação estabelecida pela Akademie Ausgabe, com exceção da Crítica da razão pura que também será citada de acordo com a paginação da segunda edição indicada pela letra B, a qual está presente na versão portuguesa da obra traduzida por Valério Rohden e Udo Moosburger.

${ }^{6}$ Esse é o tema central de todo o escrito Resposta a Eberhard: Kant. ÜE, AA 08: 185-251.

${ }^{7}$ Sobre isso ver os artigos de Korsgaard (1985) e Nell (1991).
} 
serve apenas para identificar qual máxima pode ou não ser universalizada, ele também ordena que se adote apenas as máximas que passarem pelo processo de universalização.

Ora, com base nisso pode-se perceber que as críticas de Hegel, pelo menos da forma como elas estão formuladas, não são pertinentes. Contudo, isso não significa que efetivamente a teoria kantiana consegue dar conta dos problemas que surgem com o emprego do imperativo categórico e que ela é capaz de legitimar suas pretensões. Entretanto, isso implica em uma discussão extensa e pormenorizada que vai desde qual o conceito e a função das máximas até as diferentes formulações do imperativo categórico, o que não pode ser realizado aqui ${ }^{8}$. Por exemplo, em que sentido a máxima de "Robin Hood" não poderia ser universalizada, ou seja, em que sentido eu não poderia querer que "num sistema injusto, seja correto roubar dos ricos para dar aos pobres" ou "roubar para que um determinado sistema financeiro vá à bancarrota”, ou ainda, em que sentido eu não poderia querer a máxima de "mentir, quando para isso salvo a vida de uma pessoa inocente”. A primeira vista, parece que essas máximas poderiam ser universalizadas, isto é, não parece que haja uma contradição em querer que todas as pessoas empreguem essas máximas, visto que se pode querer substituir um determinado sistema financeiro ou mesmo querer salvar a vida de uma pessoa inocente.

Quando se lê o escrito de Kant contra Benjamin Constant a respeito da mentira ${ }^{9}$, onde ele defende que se deva dizer a verdade mesmo quando a conseqüência disso seja entregar uma pessoa inocente a um assassino, consegue-se entender o porquê de Hegel afirmar que o emprego do imperativo categórico poder levar a coisas injustas e imorais. O fato de Kant não reconhecer que em determinadas situações possa ocorrer um choque de máximas morais é problemático e a forma como ele pretende ter resolvido a questão é ainda mais.

Contudo, acredito que as conclusões tiradas por Kant nesse escrito não precisam ser as únicas. Pode-se tirar outras conclusões a partir da filosofia kantiana para se lidar com problemas como o da mentira por amor da humanidade, que representa um caso paradigmático. Em outras palavras, pode-se ir contra Kant, mas ainda assim, a favor da filosofia kantiana.

\footnotetext{
8 Para uma excelente introdução a respeito desse tema ver Kerstein (2002).

${ }^{9}$ Cf. Kant. Über ein vermeintes Recht aus Menschenliebe zu lügen, AA 08: 423-430.
} 
Em primeiro lugar, a filosofia kantiana não defende a mera aplicação de normas, pois o ato da reflexão constitui um momento fundamental da atividade do sujeito moral e é condição da sua autonomia ${ }^{10}$. O sujeito tem que reconhecer ou não a universalidade de uma máxima e em seguida, através de uma decisão livre, precisa assumir ou não determinada máxima como sua. $\mathrm{Da}$ mesma forma, Kant aceita que o julgamento moral depende de uma certa habilidade do indivíduo em reconhecer que um certo caso dado se aplica a uma determinada regra. Essa habilidade de julgar não é algo que possa ser ensinado, mas precisa ser desenvolvida pela prática. Enfim, a teoria da ação moral kantiana comporta intrinsecamente momentos em que o indivíduo precisa exercer ativamente sua capacidade reflexiva, seja para decidir a respeito de suas máximas, seja para decidir se um caso particular cai sobre a regra.

Em segundo lugar, a filosofia prática kantiana reconhece, diferentemente da filosofia teórica, que nossos conceitos a priori práticos determinam o que é certo e correto na nossa ação, mas não determinam o que de fato no mundo é. Por conseguinte, diferentemente do estabelecimento das estruturas teóricas do mundo, a filosofia prática estabelece as estruturas do que deve ser, mas não daquilo que é. Contudo, a filosofia prática também pode ser considerada uma teoria, nesse sentido, seguindo-se a indicação do próprio Kant ${ }^{11}$, quando não se consegue aplicar imediatamente a teoria à prática, não necessariamente significa que a teoria esteja errada, mas que talvez ela ainda esteja incompleta, ou seja, os princípios envolvidos nas máximas de "salvar a vida de uma pessoa inocente" e de "não mentir" não entraram em choque através do desenvolvimento interno da teoria, mas porque o mundo sensível não se adéqua sempre perfeitamente aos conceitos práticos a priori e, nesse caso, a teoria precisa ser mais elaborada.

Nesse sentido, um sujeito moral kantiano, numa situação tal como aquela descrita por Constant, poderia ficar calado ou ter dado uma resposta vaga, ou seja, ele não precisaria mentir e, além disso, salvaria a pessoa inocente. $\mathrm{Ou}$ ainda, ele poderia falar a verdade e, através de um ato altruísta e heróico, poder-se-ia interpor entre a pessoa inocente e o assassino, ainda que arriscando sua vida para isso. Mas ele também poderia simplesmente ter dito

\footnotetext{
${ }^{10} \mathrm{Cf}$. "(...) e assim fica claro que o entendimento é capaz de ser instruído e abastecido por regras, mas que a capacidade de julgar é um talento particular que não pode ser ensinado, mas somente exercitado" (Kant. KrV, AA 03: 131/ B172. Também sobre isso em: Kant. TP, AA 08: 275).

11 Sobre isso ver a introdução do texto Sobre o dito comum: isso pode ser correto na teoria mas não serve para a prática: Kant. TP, AA 08: 275-277.
} 
uma mentira sem ainda ter adotado a mentira como máxima de sua ação. $\mathrm{Ou}$ seja, ele poderia continuar tendo como máxima falar sempre a verdade, pois reconhece o valor moral dessa máxima, mas mesmo assim, ele pode reconhecer que a situação o força moralmente a escolher a máxima de salvar pessoas inocentes. O que lhe obrigou a isso? A lei moral, afinal de contas, eu posso sem contradição querer que a seguinte máxima se torne uma lei universal: "salvar uma pessoa inocente de uma morte certa, ainda que tenha que mentir”. Penso que Kant estava se equivoca ao pensar que alguém estaria corrompendo sua disposição moral ao se decidir em favor da mentira numa situação específica em que outra norma moral me exige uma atitude diferente, pois se pode optar pela mentira, sem ainda transformar ela numa máxima. Ou seja, eu ainda reconheço que a máxima da mentira é imoral, mas eu percebo que num plano muito particular, o ato de mentir necessita ser subsumido à máxima de salvar a vida de um inocente.

O que Kant não quer fazer em seu texto é reconhecer que exista um direito à máxima da mentira, mas ele não percebe que pode aceitar uma mentira sem atribuir um direito a ela como uma máxima legítima. Isso pode ser feito sem que o imperativo categórico perca seu valor como critério de avaliação de máximas ou mesmo como princípio que caracteriza uma boa vontade. Entretanto é compreensível a motivação de Kant em suas posições, pois acredito que ele não queira as seguintes conclusões: 1. uma vinculação do imperativo categórico às contingências de cada situação, isto é, abrir espaço grande demais para que os indivíduos em cada situação procurem encontrar alguma exceção que tente legitimar suas intenções egoístas; 2. concordar com Constant, que afirma que o princípio de falar a verdade conduziria à impossibilidade de uma convivência social, posição da qual Kant discorda profundamente, pois no fundo ela levaria a conclusão de que o imperativo categórico implica na impossibilidade da convivência social.

No entanto, para fins jurídicos e no nível da ação externa, Kant está certo em afirmar que não se pode condenar alguém por falar a verdade, mas penso que ele está equivocado ao não reconhecer também a culpa a respeito da passividade do agente frente a uma determinada situação, ou seja, no caso criado por Constant, por exemplo, o sujeito indagado não poderia ser punido por falar a verdade, mas poderia ser punido por não tentar impedir o assassino. Assim como ele poderia ser culpado pela mentira, caso a mentira levasse ao sucesso do assassino tal como Kant problematiza, mas ainda assim 
poderia ser absolvido, caso se comprovasse que ele tentou impedir de outras formas o assassínio.

É importante perceber que essas críticas à teoria moral de Kant são feitas sempre com relação a casos limites. Mas nesse caso, pode-se pensar sempre em situações cada vez mais dramáticas. Por exemplo, imagine-se a situação em que, se eu minto, coloco a vida de uma pessoa inocente em risco, mas se eu falo a verdade, sou eu que corro o risco de morte, mesmo sendo inocente. Que fazer? Falar a verdade e me colocar num perigo de morte ou mesmo numa situação de morte certa ou mentir e viver com o fato de ter condenado à morte uma pessoa inocente? Mas antes de tudo cabe colocar a pergunta: até que ponto se pode deixar que a casuística adentre a teoria moral, seja ela qual for? Ou seria possível uma teoria a partir da casuística? Com certeza, não para Kant.

\subsection{0 uso do imperativo categórico}

A intenção da filosofia prática kantiana nunca foi estabelecer ou criar uma nova moral, mas explicitar e legitimar teoricamente os fundamentos da moralidade que já se encontram presentes nos julgamentos morais cotidianos das pessoas. Por isso a ética kantiana não tem a pretensão de apresentar um novo princípio a partir do qual se derivem mandamentos, mas sim, por um lado, apresentar um critério que sirva para testar a universalizabilidade das máximas e, por outro, legitimar a lei moral que subjaz os julgamentos éticos das pessoas.

Além disso, a crítica de Hegel implica uma compreensão equivocada a respeito do conceito de a priori em Kant. Pensar que a partir desse conceito se derive simplesmente as leis é algo equivocado. Isso fica mais claro se compararmos a filosofia teórica com a filosofia prática. $\mathrm{Na}$ filosofia teórica, por exemplo, ainda que a dedução transcendental estabeleça os princípios de uma experiência sensível em geral, não se pode, nem é da alçada da filosofia, derivar dos conceitos a priori as leis empíricas da natureza. Assim, ainda que se estabeleça a regra de causa e efeito nas Analogias da experiência ${ }^{12}$, não se chega ali à explicitação da lei da gravidade terrestre, por exemplo, pois isso é da alçada da ciência empírica. Entretanto, de forma alguma isso compromete a aprioridade da lei da causalidade e ela pode ser aplicada a todos os

${ }^{12}$ Cf. KANT. KrV, AA 03: 158-185 / KrV, B219-265. 
conteúdos empíricos, seja na gravidade terrestre ou lunar. Da mesma forma que as categorias precisam ser primeiramente esquematizadas, isto é, incorporadas nas formas puras da sensibilidade de espaço e tempo para, em seguida, funcionarem como princípios organizadores da experiência, também a filosofia prática inicia num nível abstrato e vai gradativamente tomando uma forma mais concreta, como por exemplo, nas diversas formulações do imperativo categórico.

Assim, ainda que na aplicação do imperativo categórico haja a apropriação de certos conteúdos empíricos, não são eles que determinam a conclusão sobre a universalizabilidade da máxima. Em outras palavras, a critica de Hegel de que Kant deduz a imoralidade do roubo a partir da legitimidade ou da existência da propriedade não é correta. O que Kant faz é mostrar que a máxima de um indivíduo que rouba não pode ser universalizável, pois no processo de universalização surge uma contradição interna na vontade do agente.

Quando um indivíduo simplesmente toma para si algo que era de outrem, independente da questão de se essa primeira propriedade era ilegítima ou não, ele age com base na máxima "quando eu quiser ou precisar de algo, simplesmente pego para mim”, mas essa mesma premissa já está pressupondo, por sua vez, que ele quer a instituição da propriedade. Ora, a lei moral ordena que eu tenha apenas máximas que possam ser universalizáveis. $\mathrm{O}$ indivíduo que rouba quer e não quer ao mesmo tempo a instituição da propriedade, logo a máxima de "tomar para si algo que pertence a outrem” é imoral. Claro que se este indivíduo chegar numa terra desabitada e sem dono e tomá-la para si, esse ato não constitui roubo. Nesse sentido, é óbvio que só pode haver roubo onde há propriedade, mas a imoralidade do roubo não se encontra na questão da legitimidade da propriedade ou da existência dela, mas na incapacidade de universalização da máxima. Em outras palavras, segundo a aplicação do imperativo categórico chego à conclusão de que sempre onde houver propriedade será imoral efetuar um roubo, da mesma forma que segundo a lei da causalidade posso concluir que onde algo acontece, houve pelo menos a atuação de uma causa.

\section{Recolocação das críticas de Hegel}

Muitos intérpretes da filosofia hegeliana reconhecem que as críticas de Hegel, ao menos da forma como elas se encontram explicitamente formuladas nos Princípios da filosofia do direito, não se sustentam sozinhas, 
mas necessitam de outros elementos que se encontram nessa e noutras obras. Nesse sentido, eles procuram reconstruir aquelas que seriam as verdadeiras críticas de Hegel e, com isso, também as relações positivas que existem entre a filosofia moral kantiana e o projeto hegeliano, pois como aponta Pinkard (2000, p.58-69), o jovem Hegel havia se colocado como propósito filosófico mostrar como a moralidade kantiana poderia tornar-se real, tornar-se aplicável. Mas então cabe a pergunta, se ele achava a moralidade kantiana vazia, por que querer torná-la real? Essa relação crítica positiva também fica clara pela própria estrutura do livro Linhas fundamentais da filosofia do direito. A própria estrutura do método dialético evidencia que a moralidade possui algo de positivo e que não pode ser uma mera formalidade vazia que conduz simplesmente a injustiças e imoralidades, isto é, a moralidade precisa ser superada, mas também incorporada naquilo que Hegel chamou de eticidade, tal como pressupõe o conceito de Aufhebung. Além disso, na Filosofia da história Hegel coloca a moralidade da modernidade num nível superior à eticidade dos antigos.

De fato Hegel remete a discussão no $§ 135$ para outros textos, mais especificamente a Fenomenologia do espírito (§419-437) e a Enciclopédia (§440 ff.). Os intérpretes se servem dessa referência para recolocar as críticas de Hegel sob outro prisma. No intuito de sistematizar essas leituras, pode-se dividir aquelas que seriam as verdadeiras críticas de Hegel em duas: 1) a que se dirige à tese kantiana da razão legisladora, a qual envolve desde a vacuidade de uma boa vontade até aquela que se refere à questão da motivação moral; 2) e a critica à falta de realidade da moralidade kantiana num sentido político e institucional.

\subsection{Crítica à razão legisladora}

Esta crítica é bastante complexa e possui diversas facetas. Ela se refere basicamente à capacidade da razão em ser essencialmente prática, isto é, à capacidade da razão em oferecer uma lei que seja ao mesmo tempo um imperativo, ou ainda, se dirige contra a possibilidade de um princípio sintético a priori prático. Hegel estaria colocando em cheque a capacidade da razão em oferecer uma lei que é por si mesma e suficientemente causa movente da ação. Penso que em geral a releitura de Hegel por parte de comentadores permite dividir essa crítica em dois níveis: a) num nível fundamental, que questiona a derivação da lei moral a partir de um sujeito transcendental ou do conceito de uma boa vontade; b) num nível da 
psicologia motivacional, isto é, que questiona a possibilidade da consciência da lei moral servir como móbil suficiente da ação.

\section{a) Crítica à derivação da lei moral}

Wood (1990, p.161-169) reconstrói a crítica de Hegel com base nos textos Lei Natural (1802), Fé e conhecimento (1802) e Fenomenologia do espírito (1807). Segundo ele,

Hegel pode estar errado em pensar que a fórmula da lei universal é vazia, mas ele não está errado em pensar que o ponto de partida de Kant (na idéia de uma vontade livre e de um imperativo categórico) é puramente formal e incapaz de conduzir a qualquer princípio moral determinado. (...) Se a Fórmula da lei universal não é vazia é por que ela não segue do ponto de partida, esse ponto de partida é vazio. (Wood, 1990, p.167, tradução própria)

De acordo com Wood, o argumento que deriva a fórmula da lei universal a partir do conceito de um fundamento objetivo é falacioso. A exposição de Wood não é muito clara, mas o ponto central da crítica parece ser o seguinte: Kant não pode derivar do conceito de fundamento objetivo da ação, no qual está implicado o conceito de universalidade de aplicabilidade, a consequência de que haja uma desejabilidade racional. Em outras palavras, do fato de que seja racional que cada pessoa siga um determinado princípio, não se segue que é racional que todos queiram seguir esse princípio. "Nós não podemos inferir (como Kant faz) que um princípio com universalidade de aplicabilidade é eo ipso um princípio com racionalidade coletiva"13, isto é, um princípio que quando seguido por todos "resultaria em um sistema de comportamento coletivo que é racional e genericamente benéfico"14. Ou ainda, "a priori não temos forma alguma de descartar a possibilidade de que um princípio com aplicabilidade universal possa ditar para cada indivíduo um curso de ação que ele não possa querer que outros também deveriam seguir” ${ }^{15}$, tal como aconteceria com o princípio da felicidade egoísta.

\footnotetext{
13 WOOD, 1990, p. 166.

${ }_{14}$ WOOD, 1990, p.165.

15 WOOD, 1990, p. 166.
} 
Sedgwick (1996), por sua vez, afirma que a crítica hegeliana ao imperativo categórico deve ser vista como um desdobramento mais amplo da crítica ao idealismo transcendental como um todo. Para isso, a intérprete procede sua argumentação da seguinte forma: primeiro, identifica a crítica hegeliana à teoria do conhecimento de Kant, a qual se refere diretamente à Dedução transcendental das categorias, segundo, mostra que a solução apontada pelos intérpretes para defender Kant das críticas de Hegel depende do resultado da argumentação da terceira antinomia, a qual, por sua vez, pressupõe a validade da dedução transcendental das categorias, o que, por conseguinte, vincula a mesma crítica realizada à dedução das categorias à "dedução" do imperativo categórico como uma lei a priori da razão. Em suma, ela pretende levar a discussão da vacuidade do imperativo categórico para o campo de disputa da própria possibilidade do idealismo transcendental ${ }^{16}$. Segundo Sedgwick, Hegel vê no idealismo transcendental de Kant um pressuposto equivocado, a saber, um princípio que ele compartilha com o empirismo, qual seja, o da não unidade do múltiplo dado empiricamente (no-unity-in-content principle). Esse princípio estaria baseado sob duas pressuposições: primeira, que o conteúdo dado na percepção é "algo multifacetadamente concreto" e assim não contém dentro de si uma unidade; segunda, a idéia de que o conteúdo dado na percepção é nossa única fonte de material ou conhecimento não conceitual. Assim,

O universal não é para ser descoberto no conteúdo da percepção, e uma vez que Hume pense que o conteúdo da percepção é tudo o que temos e sobre o qual podemos basear nosso conhecimento da experiência, o empirismo, na medida em que ele é consistente, é forçado em sua descrição a concluir a injustificabilidade de suas afirmações empíricas. (Sedgwick, 1996, p. 571, tradução própria)

Entretanto, apesar do idealismo transcendental kantiano compartilhar dessas premissas, ele não quer extrair como consequência o ceticismo humeano. Mas, segundo Hegel, mesmo as intuições e percepções já requerem a capacidade de discriminação da cognição, a qual é sempre uma unificação ou um processo de abstrair a partir de um particular "este". Então, os

${ }^{16}$ SEDGWICK, 1996, p. 578. 
empiristas estão equivocados tanto em sua compreensão a respeito da natureza da percepção, quanto naquilo que eles identificam como seu objeto. Em outras palavras

Hegel argumenta que forma e conteúdo são originalmente partes da mesma unidade. Eles se tornam separadas apenas como o resultado de um ato de abstração. Forma, então, é não mais originalmente independente do conteúdo do que o conteúdo da forma. Assim, Hegel procura minar neste sentido não apenas o empirismo kantiano sobre conteúdo, mas também sua concepção daquilo que nós podemos chamar de autonomia da razão e de suas leis. (Sedgwick, 1996, p. 577, tradução própria)

Em suma, a crítica de Hegel ao formalismo transcendental kantiano iria de encontro com a intuição fundamental de Kant de que haveria um conteúdo a priori, seja ele dado no entendimento, seja na razão. Por isso, segundo Hegel, Kant não consegue extrair deveres unicamente da razão, isto é, o imperativo categórico é sem conteúdo por que a própria razão transcendental é vazia. Para Hegel forma e conteúdo precisam ser unificados numa nova forma de idealismo, no qual o intelecto humano possui um acesso às coisas tal como são em si mesmas.

\section{b) Crítica ao âmbito motivacional}

Geiger (2004, p.130-134; 2007, p.9-32) retoma a crítica de Hegel com base nos $\S \S 419-428$ da Fenomenologia do espírito. Segundo ele, Hegel não concorda com a estrita divisão proposta por Kant entre móbeis sensíveis, os quais conduziriam sempre a ações heterônomas, e o reconhecimento da lei moral enquanto o único móbil da ação moral. Nessa perspectiva, Hegel discorda de que as nossas inclinações jamais possam fundamentar atos morais, ou seja, que elas não pudessem ser reformuladas de modo que a moralidade se tornasse um verdadeiro hábito. Para Kant, há sempre a necessidade de um reconhecimento reflexivo da lei moral e da universalizabilidade da máxima para que um ato seja moral, logo, a moralidade não pode criar raízes e toda ação moral é uma ação primeira ${ }^{17}$.

${ }^{17}$ Cf. "A moralidade está sempre em progresso e inicia sempre do início" (Kant. Die Metaphysik der Sitten, AA 04: 409). 
Nesse sentido, Geiger (2004, p.128), com base na distinção entre dois conceitos de vazio em Hegel, interpreta a crítica de Hegel sobre a vacuidade da filosofia moral kantiana no sentido de "falta de realidade" e não de "falta de articulação conceitual”. Em outras palavras, pela falta de uma força movente que a moralidade kantiana não pode ser tornada real. Assim, Hegel estaria buscando um fundamento intermédio entre a ação baseada conscientemente na lei moral e uma resposta não reflexiva baseada simplesmente no hábito. Essa resposta é encontrada precisamente no amor, que é chamado a cumprir a função de unificação entre a lei e a inclinação (Geiger, 2004, p.132).

Também Wood (1997, p.155-157) aponta para isso. Segundo ele, Hegel criticaria a perspectiva moral por apresentar uma visão contrastante da vida humana, pois a moralidade cinde o ser humano em dois. Já a vida ética busca uma harmonia, onde a virtude é vista como a capacidade e a disposição inteligente de fazer aquilo que se deve. A perspectiva moral coloca a inclinação e o dever um defronte ao outro, enquanto que a perspectiva da vida ética defende que ação eticamente genuína é aquela que consegue engajar a natureza do agente em todos os níveis, tanto da paixão e dos desejos sensíveis quanto da razão. Assim, Hegel considera que tratar a razão e a inclinação como indiferentes ou hostis entre si reduz a moralidade a um vazio "deve", o qual torna impossível um agir de fato, ou mesmo atribuir um conteúdo no nível da ação. A perspectiva da moralidade estaria condenada à hipocrisia, pois ela acreditaria numa impossibilidade, a saber, que uma ação pudesse ser comandada independentemente da consideração do aspecto sensível do sujeito em questão. Segundo Wood (1989, p.8-11; 1990, p.169172), o argumento básico seria que a ação moral não pode ser uma pura determinação do dever pelo dever, por que toda vez que eu determino um dever em particular, estou determinando o fim de uma ação, tal como o de não mentir num determinado caso, logo a moralidade não é pura, pois há sempre um conteúdo particular dado pelo contexto da ação, o qual é expresso no fim da ação, isto é, na sua finalidade. O próprio Kant reconhece que toda ação também pressupõe um fim, sendo que inclusive existem alguns fins que são também deveres. A diferença de Kant e de Hegel estaria em que, com base numa psicologia motivacional baseada no princípio de causa e efeito, Kant rejeita que uma ação moral seja determinada por outros motivos a não ser os da representação da lei moral, enquanto para Hegel, que baseia sua psicologia motivacional numa descrição de intenções (Cf. Wood, 1990, 
p.140-152), não teria problemas em aceitar que uma ação moral poderia ser realizada por uma série de intenções, inclusive auto-satisfação. Em suma, a tese de Hegel é a de que agir com base num princípio com conteúdo é sempre agir a partir de motivos empíricos (inclinações, interesses, paixões) e querer fugir disso significaria ou não agir, ou abstrair completamente do conteúdo empírico da ação, o que tornaria a ação completamente indeterminada quanto ao seu fim.

Outro autor que menciona a crítica de Hegel nos termos da motivação moral é Ameriks (2000, p.309-337). Segundo ele, a principal crítica de Hegel à moralidade kantiana se refere à relação estabelecida entre o conceito de sumo bem e à sua influência na ação moral. Em outras palavras, para Ameriks o principal aspecto da crítica de Hegel a Kant se refere ao postulado kantiano de que "a virtude merece felicidade". Para Hegel, "o componente da felicidade no sumo bem significa introduzir 'dissimulação', inconsistência e hipocrisia para os kantianos"18. Segundo Ameriks,

o problema é exacerbado aqui devido à característica crucial da teoria ética kantiana, a saber, que uma atitude, assim como qualquer objeto, pode ter valor moral apenas se é buscado com a intenção adequada. Mas se agora a atitude em questão é a 'disposição de ânimo' geral de alguém, então dizer que alguém está transformando isto é dizer que alguém precisa fazer a transformação com uma boa intenção. Mas isto é algo que é ex hypothesi impossível, pois o que falta para ele é precisamente a intenção requisitada; se ele tem isso, ele já teria a correta 'disposição de ânimo' e não necessitaria de 'revolução’”. (Ameriks, 2000, p.337, tradução própria).

Em outras palavras, haveria um problema grave de petição de princípio na teoria kantiana da motivação moral, mais especificamente, na formulação da teoria a respeito da "revolução da disposição de ânimo", teoria que Kant apresenta pela primeira vez na Religião nos limites da simples razão e na Metafísica dos costumes, a qual procura dar conta da possibilidade da superação do mal radical que se encontra incrustado na disposição de ânimo do ser humano.

${ }^{18}$ AMERIKS, 2000, p.333-334. 


\subsection{Crítica ao âmbito político-institucional}

Segundo Geiger $(2004 ; 2007)$ a crítica de Hegel à moralidade kantiana tem também como alvo a cisão que Kant estabelece entre doutrina da virtude e doutrina do direito, a qual, segundo ele, tem como fundamento a posição internalista que assume a moralidade. A partir dessa perspectiva de uma boa vontade, a moralidade kantiana falha em oferecer um critério para decidir qual dos arranjos políticos e sociais se deve estabelecer. Nesse sentido, tornar a moralidade real, nos termos hegelianos, seria realizá-la em instituições políticas e sociais de uma forma de vida compartilhada de acordo com a disposição ética de seus membros. Em outras palavras, a moralidade kantiana careceria de conteúdo pelo fato dela não conseguir se realizar institucionalmente.

Também Pippin (1991, p.108) aponta para esse aspecto da crítica de Hegel. Em seu artigo, ele mostra como a posição kantiana e a posição hegeliana se originam de uma raiz comum, isto é, a partir da tentativa de responder ao problema colocado por Rousseau, a saber, de como uma vontade pode ser auto-legisladora sem criar ao mesmo tempo auto-alienação. Segundo Pippin, Hegel veria a solução kantiana como problemática, pois ela alienaria o sujeito em detrimento de um eu puro, ou seja, a sujeição da vida real a um ideal vazio e hipócrita. A saída apresentada por Hegel para a questão da autonomia seria que a realização da liberdade só pode ser alcançada quando o sujeito compreende a relação da sua conduta com o papel das instituições e das regras sociais que constituem o estado moderno.

\section{Possíveis tentativas de uma resposta kantiana}

Querer responder completamente as críticas apresentadas sumariamente acima significa ter expectativas demasiadamente altas para um único texto. $\mathrm{O}$ máximo que se pode fazer aqui são algumas indicações de respostas, pois o espectro no qual os comentadores reapresentam a crítica de Hegel não é nada menos do que toda a filosofia transcendental, desde seus fundamentos até os desdobramentos últimos da filosofia moral.

\section{1 - Sobre a razão legisladora}

A recolocação das críticas de Hegel neste âmbito coloca a discussão no cerne das problemáticas que envolvem as interpretações contemporâneas da 
filosofia moral kantiana. Não se tem a pretensão aqui de reconstruir interpretações contemporâneas a respeito desse ponto, mas esboçar os traços gerais de uma possível resposta.

\section{a) Sobre a derivação da lei moral}

Wood procura mostrar que haveria uma lacuna na derivação da lei moral tanto na Fundamentação da metafísica dos costumes quanto na Crítica da razão prática. Essa lacuna seria basicamente entre a universalidade de aplicabilidade e a desejabilidade universal, termos criados por Wood para expressar dois aspectos distintos da lei moral. Segundo ele, a vinculação desses dois aspectos seria desenvolvida por Kant na segunda seção da Fundamentação e corresponderia ao primeiro passo da derivação da lei moral. Acredito que essa leitura é equivocada, pois ela não considera aquilo que é desenvolvido por Kant na primeira seção da Fundamentação, pois é ali que ele retira do conceito de uma boa vontade a primeira formulação da lei moral, enquanto que na segunda secção da Fundamentação ele desenvolve o conceito de lei tendo em vista a perspectiva de seres racionais sensíveis, para os quais a lei precisa se tornar um imperativo e, além disso, onde se encontram as diversas formulações do imperativo. Quando Kant inicia com o conceito de uma boa vontade para dele estabelecer suas principais notas, já fica implicado na argumentação que a universalidade da máxima também se constitui numa desejabilidade universal, pois desde o início está se tratando com a universalidade de um querer e não simplesmente com a universalidade de um pensar.

Kant realiza a derivação da lei moral partindo de uma separação genealógica dos elementos envolvidos na vontade. Uma vontade sempre se expressa num querer de algo. Esse algo pode ser diverso, mas quando se trata de um querer de uma boa vontade, o querer não é determinado por nenhum conteúdo material, mas é um querer que quer a si mesmo, isto é, trata-se de uma vontade que não se determina por algum objeto externo a ela, mas se determina por sua própria forma, que é o seu aspecto universalizável. Nesse caso, a máxima que orienta a vontade a ser determinada por sua forma e não por um objeto é traduzida na lei moral, isto é, na orientação para que a máxima da ação possa ser universalizável, o que significa o mesmo que dizer que a vontade deve ser determinada por sua forma universal e não por seu conteúdo que é contingente. $\mathrm{O}$ princípio que exige que a máxima da ação seja considerada como uma lei universal é o mesmo que exige que a máxima 
da ação seja tal que a vontade seja sempre determinada por sua forma e não por seu conteúdo. Logo, o princípio de agir tal como se sua máxima fosse uma lei da natureza pode ser traduzido pelo princípio de uma vontade que se auto-determina, o que faz com que na lei moral já estejam simultaneamente embutidos, tanto os princípio da universalidade, quanto da desejabilidade, que é o atributo central da boa vontade.

Wood argumenta utilizando o exemplo de um indivíduo egoísta que poderia querer que sua máxima fosse desejada por todos, mas que ela não é por isso universalmente aplicável. Entretanto, o exemplo que ele dá, já parte de um ponto de partida equivocado. Pois a máxima de um sujeito egoísta não é determinada pelo princípio formal, mas pelo princípio material da felicidade própria. Wood está errado ao afirmar que a aplicabilidade universal não está vinculada com a desejabilidade racional. $\mathrm{Na}$ medida em que o ser racional se determina por uma máxima que contém a lei moral, ele também irá querer os resultados que se seguem desse princípio quando ele for adotado por todos os seres racionais e isso simplesmente pelo fato de que ele, enquanto um ser racional em geral, quer apenas aquilo que sua vontade racional quer, isto é, quer a si mesma e não querendo nada que possa impedila de exercer essa liberdade: ele quer sua autonomia.

Wood (1990, p.166) prevê essa crítica, no que ele chama de interpretação forte do primeiro passo da derivação da lei moral. Mas segundo ele, essa interpretação falharia pelo fato de tornar o segundo momento da derivação da lei moral supérfluo. Quanto a isso, posso dizer que ele não compreende corretamente qual é o segundo momento da dedução da lei moral, o qual é o principal, a saber, o significado de se afirmar que existe um juízo sintético a priori prático, ou ainda, que a lei moral obrigue ${ }^{19}$. O sujeito, enquanto ser racional em geral, reconhece a validade da lei moral e também reconhece que os efeitos da sua ação serão desejáveis em um mundo em que todos sigam essa lei, mas pra ele, enquanto ser racional sensível, a lei não possui uma atuação imediata, isto é, ela precisa mais do que simplesmente o reconhecimento de que ela é universalizável e de que seria bom se todos agissem de acordo com ela. Precisa-se mostrar que ela tem tal efeito sobre seu ânimo de modo que ela seja capaz de constrangê-lo em situações em que, mesmo sabendo que sua ação permanecerá em segredo, mesmo assim, ele não

${ }^{19} \mathrm{O}$ segundo momento da derivação da lei moral é realizado essencialmente por Kant em: Kant. KpV, AA 05: 42-49. 
queira abrir uma "exceção" para si na legislação moral e tirar uma vantagem egoísta da situação. Em suma, não acredito que Wood tenha conseguido demonstrar que há uma lacuna na derivação do conteúdo da lei moral, pois na "boa vontade" a universalidade e a desejabilidade estão unidas desde o início, sendo que, na verdade, é no segundo momento da derivação da lei, o da obrigatoriedade, que surge a figura do fato da razão, o verdadeiro ponto delicado da filosofia prática kantiana.

A respeito da crítica colocada por Sedgwigk não se pode dizer muito. De fato Kant assume como ponto de partida que o múltiplo dado na intuição empírica e sensível não possui unidade, mas que a unidade se dá a partir de um processo ativo do sujeito cognoscente. Mas a outra possibilidade seria partir do pressuposto de que a unidade já se encontra dada no objeto. Isso, para Kant, significaria uma recaída para uma metafísica pré-crítica e dogmática, pois não se tem como legitimar a possibilidade de um conhecimento a priori, isto é, necessário e universal sobre fenômenos a não ser que se pressuponha uma harmonia pré-estabelecida, como ocorre num bem ordenado cosmos grego (Platão e Aristóteles), ou sob a pressuposição de um criador do mundo sábio e todo poderoso (à la Descartes), ou mesmo um espírito absoluto que se desenvolve teleologicamente.

\section{b) Sobre a motivação moral}

As críticas levantadas por Geiger e Wood, a respeito da cisão provocada pela moralidade kantiana e da incapacidade de uma ação ser realizada sem qualquer móvel sensível, ou ainda, de que a moralidade kantiana não prevê a possibilidade de uma reeducação das inclinações sensíveis são complexas e envolvem vários aspectos.

Em primeiro lugar, é importante ter em mente que a ética kantiana não tem a pretensão de ser essencialmente uma ética da avaliação moral da ação, mas das máximas, isto é, ela não pretende servir de base para que a sociedade ou mesmo o próprio indivíduo avaliem moralmente seus atos, mas sim suas máximas. Na medida em que é impossível saber com certeza qual foi o verdadeiro móbil da ação ${ }^{20}$, isto é, qual foi a máxima que determinou de fato a ação, a perspectiva de avaliação moral da ação fica inviabilizada e, por isso, bastante problemática. Ora, se a ética kantiana se foca nas máximas da ação e não na ação mesma, o que está em questão desde o início é que o

${ }^{20}$ Cf. GMS, AA, 04: 407. 
indivíduo jamais deve dramatizar a respeito da sua ação, seja para terceiros, seja para si próprio. O que realmente importa, na verdade, é que ele se esforce continuamente por agir de acordo com máximas que estão de acordo com a lei moral, independentemente da situação, havendo ou não empecilhos para isso. Esse aspecto é pouco considerado pelos leitores de Kant, porém é muito importante. Se não cabe julgamento moral da ação em sentido estrito, isso não significa que a ação não possa ser valorada de outra forma, segundo as regras do direito ou segundo as regras dos costumes. O ponto é que não se pode ter a pretensão de se auto-outorgar ou outorgar a outros, seja valor moral, seja o status de virtuoso, mas, novamente, o que se pode fazer é apenas e continuamente se empenhar nesse caminho e interpretar as ações aparentemente virtuosas dos outros como exemplos que fortalecem nossa disposição. Uma vez que esse aspecto fique acentuado, então fica sem sentido dizer que para a filosofia moral kantiana as inclinações sensíveis corrompem necessariamente a atitude moral ${ }^{21}$, pois, afinal de contas, se eu não posso determinar exatamente quais são os móbeis da minha ação e se eu não posso me obrigar a deixar de deseja alguma coisa, essa crítica fica sem sentido.

Kant acentuou várias vezes a importância de sentimentos benéficos, como o amor, a benevolência e a filantropia para uma antropologia e uma pedagogia da educação moral. Entretanto, esses sentimentos, ainda que sejam importantes, ocupam apenas um papel secundário na teoria moral kantiana. Isso se deve pelo objetivo central de Kant ser o de fundamentar o princípio da moralidade e mostrar de que forma ele ordena, independentemente do fato da possibilidade de se saber se ele de fato operou numa determinada situação. Em suma, a cisão realizada por Kant entre sensibilidade e razão prática, a qual foi tão difamada por seus críticos, opera num nível da legitimação e justificação e não no nível da explicação de uma determinada ação moral.

Quanto à questão da reformulação das disposições ou se a moralidade pode ou não se tornar habitual, trata-se também de um ponto complicado. Mas uma resposta que se pode dar é que, mesmo considerando que Kant estivesse errado a respeito da possibilidade do sujeito reeducar suas inclinações sensíveis para que elas trabalhem em prol da moralidade, ainda assim, essas inclinações sensíveis poderiam colaborar, mas não poderiam substituir o reconhecimento da lei moral e o papel do respeito na ação

${ }^{21}$ Um aspecto dessa discussão está em meu texto Klein (2009). 
moral. Em outras palavras, ainda que houvesse uma reeducação da sensibilidade e que isso auxiliasse o agir moral, quando não houvesse $o$ reconhecimento da lei moral como sendo o móbil central da ação, então a ação não seria moral. Ora, Kant jamais diz que uma ação baseada na filantropia ou no amor seja ruim, na verdade ele afirma que essas ações devem ser valorizadas como boas e incentivadas, mas elas não tem um valor moral. Além disso, as ações sempre podem ser julgadas com base nos critérios do direito ou dos costumes, sendo consideradas justas ou injustas, legais ou ilegais, adequadas ou não aos costumes, mas nenhuma dessas categorias se identifica com a categoria da valoração moral. Afinal, qual o problema em afirmar que algo mesmo sendo bom, individual ou socialmente aceito, não possui valor moral? Por outro lado, não seria uma pretensão excessiva, quase moralista, querer expandir o valor moral da ação não apenas para máxima em questão, mas para o que se sente, ou mesmo para os efeitos ou para as consequências da ação? Não seria autoritário e absolutista dizer que o valor moral precisa se dar com base não apenas no reconhecimento da lei moral, mas numa satisfação sensível ou num reconhecimento das instituições sociais, tal como faz Hegel?

Já as críticas levantadas por Ameriks e Wood a respeito de que a ação moral sempre precisa considerar condições empíricas dadas, não me parecem procedentes a partir da perspectiva kantiana. Pelo fato de que toda ação implica em um fim, isso não transforma o princípio determinante da ação em empírico, ou mesmo compromete a aplicação do imperativo categórico. Ameriks diz que os kantianos deveriam considerar mais seriamente essa crítica de Hegel, mas talvez os hegelianos devessem levar mais a sério a perspectiva da filosofia transcendental. Para explicar um pouco esse ponto, permita-se realizar uma analogia. É difícil encontrar alguém que questionaria a validade universal e necessária da soma " $2+2=4$ ", independentemente se no fim da operação o que está em questão são bois, árvores, grãos, pedras, casas... Ou alguém questionaria a aprioridade do princípio subjacente a soma, só por que ela está computando objetos distintos? Apesar da filosofia kantiana ter uma apresentação bastante acadêmica e defender pontos de partida não intuitivos para o senso comum, ela sempre procura salvaguardar as consequências intuitivas do senso comum, tal como o fato de que não importa os objetos em questão, o juízo " $2+2=4$ " sempre é verdadeiro e, além disso, estabelece uma verdade a respeito do mundo fenomênico. Claro que, como já foi ressaltado acima sobre a questão da ampliação da teoria para 
garantir a sua aplicabilidade prática, a situação concreta pode mostrar que a soma correta para uma determinada situação não é " $2+2=4$ ", mas " $2+6-4=4$ ", isto é, a situação empírica concreta pode acrescentar complexidade ao procedimento, mas nem por isso mina a pureza do princípio subjacente, ou ainda, as condições empíricas não comprometem a validade universal do princípio responsável pelo status do procedimento. De forma análoga, na filosofia moral, os fins da ação e as peculiaridades de cada situação não comprometem a pureza do princípio que ordena a avaliação das máximas segundo sua universalizabilidade.

Já a crítica apresentada por Ameriks a respeito da teoria do mal radical e da sua superação é de fato algo que fica sem uma resposta mais completa nos escritos de Kant, contudo, pode-se tentar uma resposta a partir deles, qual seja: que o estabelecimento da máxima fundamental que determina a constituição de ânimo do indivíduo é, no fim das contas, fruto de uma atitude livre do indivíduo. Em outras palavras, o indivíduo decide, através de uma escolha livre, tornar-se verdadeiramente livre. Apesar de parecer um contra-senso, tratam-se na verdade de dois conceitos distintos de liberdade, o primeiro da liberdade do arbítrio, uma liberdade ampla e fundamental que diz respeito à liberdade de fazer e deixar de fazer em geral, e, num segundo momento, o conceito de liberdade da vontade, enquanto a verdadeira liberdade, a qual caracteriza a boa vontade ou a vontade autônoma, isto é, aquela vontade que age a partir da lei moral. Em suma, acredito que Kant pensa que não é possível oferecer uma explicação de como de fato ocorre o estabelecimento da máxima fundamental, mas que se pode justificar o porquê dela ser possível e necessária, pois cabe à liberdade do arbítrio do sujeito a característica fundamental de decidir-se, ou em prol das suas intenções egoístas, ou em prol da moralidade. Nesse sentido, da mesma forma que acontece com o "eu transcendental" na dedução das categorias, também se chega a uma pressuposição necessária de que precisa ser possível uma revolução na disposição de ânimo. Ainda que seja uma pressuposição necessária, para a qual não se pode criar uma teoria explicativa, já que se está tratando de algo que fica no campo do noumenon, pode-se estabelecer a legitimidade de se assumir essa possibilidade com base nas conseqüências para a teoria. Seria algo como uma condição transcendental para a possibilidade da liberdade, no sentido de autonomia. 


\subsection{Sobre a realização político-institucional}

Geiger (2004; 2007) e Pippin (1991) interpretam a crítica hegeliana da vacuidade do imperativo categórico como uma crítica à realizabilidade político-institucional da ética kantiana. Ora, essa crítica faz sentido da perspectiva de quem assume que é necessário que a moralidade, para que ela tenha conteúdo, determine ou constitua uma realidade exteriorizada e institucionalizada. A perspectiva kantiana não exige isso, mas nem por isso desconsidera a realidade político-institucional. Kant não nega que a moralidade deva buscar uma realidade exterior, ele apenas não a subordina ao critério de sua realidade exterior. Ele pensa que o modo correto de avaliar as ações, vistas de uma perspectiva externa, se dá com base no direito, que por sua vez é distinto da moral, ainda que não contrário a ela. O que precisa ser realizado nas instituições é o direito e Kant não veria nenhum problema em dizer que seria bom que o indivíduo reconhecesse como seu os princípios que subjazem às instituições sociais da comunidade da qual ele faz parte. $\mathrm{O}$ que Kant não exige é que esse reconhecimento precise se ocorrer necessariamente no nível, ou da sensibilidade (num sentimento de pertença ou de felicidade), ou das máximas do sujeito, ou seja, o indivíduo pode seguir as regras das instituições sociais sem necessariamente precisar se sentir completamente parte delas, ou segui-las por puro respeito (no sentido kantiano do termo). O medo, o cálculo utilitarista podem ser motivos legítimos para que o indivíduo cumpra seu dever frente às instituições políticas. Kant não vê problema nisso, pelo menos não no nível primário da ação mesma, mas sim na perspectiva de uma avaliação e melhoramento das instituições mesmas, ou seja, da perspectiva da ação não importa que o indivíduo faça algo por que reconhece a lei do país como sua máxima ou se ele age por um cálculo utilitarista, mas da perspectiva de uma avaliação das instituições políticas, é importante que os indivíduos consigam ver as regras delas como se elas fossem suas. Kant reconhece que isso seria excelente para o estado, mas não necessário para seu funcionamento 22 .

Além disso, Kant em sua filosofia da história procura conciliar sua teoria moral junto com a sua realização histórica, mas novamente, para isso ele não subordina sua teoria moral à questão da sua realização histórica.

\footnotetext{
22 Kant afirma que mesmo um povo de demônios poderia viver em um estado: Kant. ZeF, AA 08: 366. Veja-se também a sua defesa do político moral, por exemplo: Kant. ZeF, AA 08: 370-386.
} 
Nesses textos, ele teoriza a respeito de como é possível pensar legitimamente a possibilidade da realização empírica da moralidade e inclusive apresenta indícios históricos que poderiam ser interpretados como sustentando que de fato a humanidade se encontra num constante progresso moral, o qual se expressa num aprimoramento das suas instituições político-jurídicas ${ }^{23}$.

Kant pensou a respeito da questão da realização da moralidade ou sobre como os princípios da moralidade e do direito podem se conciliar de fato nas instituições sociais e políticas. Entretanto, o modo como ele lida com esse problema sempre parte do pressuposto de que agir moralmente é uma capacidade do indivíduo enquanto tal, independentemente das circunstâncias das instituições da sociedade em que ele está inserido.

O sujeito moral kantiano é aquele que se preocupa em primeiro lugar com o estabelecimento de máximas morais que orientam sua ação, mas nem por isso ele descuida da realização da sua ação ou de como ele pode melhorar as instituições políticas da sua sociedade, ele apenas as coloca num segundo momento de sua reflexão. Pensar que o sujeito moral kantiano não se importa com o que acontece à sua volta se constitui numa visão distorcida e parcial $^{24}$. Em outras palavras, a subordinação do externo ao interno não implica em um descuido ou desconsideração do externo, mas possibilita, por outro lado, que o sujeito saiba o que significa agir moralmente independentemente das circunstâncias históricas e casuais, sem escusas a respeito de que talvez seja difícil vislumbrar todos os efeitos da cadeia causal que ele põe em curso com sua ação ou sobre sua incapacidade de entender o "verdadeiro espírito" de sua época. Afinal de contas, cabe deixar aqui aberta a questão sobre o que de fato é mais realizável: a ação com base no princípio de que um ser racional deve ser considerado sempre também como fim e nunca apenas como meio, ou a ação que pressupõe tanto a compreensão a respeito das variáveis que podem ou não estar atuando num determinado contexto, quanto a compreensão a respeito daquilo que constitui o espírito de uma determinada sociedade e das instituições que a compõe?

\footnotetext{
${ }^{23}$ Cf. KANT. TP, AA 08: 307-313.

${ }^{24} \mathrm{Na}$ fundamentação Kant deixa claro que ele pressupõe que o sujeito moral é aquele que realmente quer algo, e não simplesmente deseja, nesse sentido, pode-se dizer que o sujeito moral é aquele que procura de todas as formas realizar a sua máxima, isto é, fazer que os seus fins sejam alcançados empiricamente. Cf. KANT. GMS, AA 04: 394.
} 


\section{Ponderação inconclusiva a respeito do debate}

Analisando os argumentos e as posições apresentadas acima se pode, ao menos, concluir uma coisa, que se trata de um debate árduo e que envolve mais pressupostos do que à primeira vista se poderia pensar ou mesmo reconhecer nas palavras de Hegel em Linhas fundamentais da filosofia do direito. Cada um dos argumentos e contra-argumentos poderia ser desvelado num texto independente, pois possui grandeza e dificuldade o suficiente para isso. Entretanto, alcançou-se o objetivo proposto ao apresentar um mapeamento acerca de uma problemática de grande relevância e atualidade filosófica.

A respeito dos argumentos apresentados acredito que, em primeiro lugar, as críticas de Hegel, pelo menos como são recolocadas por seus intérpretes, possuem grande relevância e atingem os pontos mais sensíveis da teoria kantiana. Por outro lado, penso que é possível sustentar uma resposta kantiana para essas críticas, ainda que aos olhares hegelianos essa resposta não seja suficiente. Em segundo lugar, tendo a fazer minhas as palavras de Smith, que afirma que "Kant foi atacado por subordinar aquilo que Hegel atribuiu supremacia. Nesse sentido a validade última da crítica de Hegel a Kant é dependente da viabilidade do próprio sistema de Hegel”25. Se isso for correto, então a crítica de Hegel à moralidade de Kant é, no fundo, um reflexo de uma oposição fundamental que se expressa em sistemas e métodos filosóficos distintos. Eis então a questão: o que se sustenta melhor, uma metafísica transcendental ou uma metafísica do espírito absoluto?

\section{REFERÊNCIAS BIBLIOGRÁFICAS:}

AMERIKS, K. "The Hegelian Critique of Kantian Morality". In: Kant and the Fate of Autonomy: Problems in the apropriation of the Critical Philosophy, Cambridge, 2000, p. 309-337.

GEIGER, I. "Hegel's critique of Kant's practical philosophy: moral motivation and the founding of modern state". In: International Yearbook of German Idealism 2, 2004, p. 121-149.

${ }^{25}$ Smith, 1973, p.440. 
. The founding act of modern ethical life: Hegel's critique of Kant's moral and political philosophy. California: Standford University Press, 2007. HEGEL, G. W. F. Grundlinien der Philosophie des Rechts. Frankfurt am Main: Suhrkamp, 1986.

KANT, I. Die Metaphysik der Sitten. In: Akademie Textausgabe, Bd. VI. Berlin: de Gruyter, 1968. Traducción de Adela Cortina Orts y Jesus Conill Sancho. 3.ed. Madrid: Tecnos, 1989.

.Die Religion innerhalb der Grenzen der bloßen Vernunft. In: Akademie Textausgabe, Bd. VI. Berlin: de Gruyter, 1968. Tradução Artur Morão. Lisboa: Edições 70, 1992.

. Grundlegung zur Metaphysik der Sitten. Einl. und Hrsg. von Bernd Kraft und Dieter Schönecker. Hamburg: Felix Meiner, 1999 (Philos. Bibliothek Bd. 519). Tradução de Paulo Quintela. In: Kant II. São Paulo: Abril Cultural, 1980.

Kritik der praktischen Vernunft. Hrsg. von Horst D. Brand und Heiner F. Klemme. Hamburg: Felix Meiner, 2003. Tradução de Valerio Rohden. São Paulo: Martins Fontes, 2002.

Kritik der reinen Vernunft. Hrsg. von Jens Timmermann. Hamburg: Felix Meiner, 1998. Tradução da edição B de Valerio Rohden e Udo Baldur Moosburger. In: Kant I. São Paulo: Abril Cultural, 1980. (Coleção os pensadores).

.̈̈ber eine Entdeckung, nach der alle neue Kritik der reinen Vernunft durch eine ältere entbehrlich gemacht werden soll (Eberhard). Bd. VIII. Berlin: de Gruyter, 1968.

. Über den Gemeinspruch: Das mag in der Theorie richtig sein, taugt aber nicht für die Praxis. In: Akademie Textausgabe, Bd. VIII. Berlin: de Gruyter, 1968. In: A paz perpétua e outros opúsculos. Lisboa: Edições 70, 2004.

. Über ein vermeintes Recht aus Menschenliebe zu lügen. Bd. VIII. Berlin: de Gruyter, 1968. In: A paz perpétua e outros opúsculos. Lisboa: Edições 70, 2004.

. Zum ewigen Frieden. Bd. VIII. Berlin: de Gruyter, 1968. In: A paz perpétua e outros opúsculos. Lisboa: Edições 70, 2004. 
KERSTEIN, S. Kant's search for the supreme principle of morality. Cambridge: Cambridge University Press, 2002.

KLEIN, Joel T. “A relação entre 'dever' e 'inclinação' na primeira seção da Fundamentação da metafísica dos costumes”. In: Anais do V Simpósio Internacional Principia, NEL/UFSC, 2009, p.319-325. Ver: http://www.cfh.ufsc.br/ nel/vol9.html.

KORSGAARD, C. Kant's formula of universal law. In: Pacific Philosophical Quarterly. n. 66, 1985, p. 24-47.

KNOX, T. M, “Hegel's attitude to Kant's Ethics”. In: Kant-Studien, n.49. 1957-1958, pp 70-81.

NELL, O. Acting on Principle. An essay on kantian ethics. New York: Columbia University Press, 1975, chapters 1-5.

PIPPIN, R. B., "Hegel, ethical reasons, kantian rejoinders". In: Philosophical Topics, 19:2. 1991: Fall, pp 99-132.

PINKARD, T. P. Hegel: a biography. Cambridge: Cambridge University Press, 2000.

RITTER, J. "Moralität und Sittlichkeit. Zu Hegels Auseinandersetzung mit der Kantischen Ethik". In: KAULBACH, F.; RITTER, J. (Hrsg.). Kritik und Metaphysik. Studien. Berlin, 1966, p. 331-351.

SEDGWICK, S. "Hegel's critique of Kant's empiricism and the categorical imperative". In: Zeitschrift für philosophische Forschung, Band 50, n. 4, p.563-584, 1996.

SMITH, J. E. "Hegel's critique of Kant". In: The review of Metaphysics, v.26, n.3, 1973, p.438-460.

WILD, A. Autonomie und Anerkennung: Hegels Moralitätskritik im Lichte seiner Fichte-Rezeption. Stuttgart: Klett-Cota, 1982.

WOOD, A. W. "Hegel's critique of morality". In: SIEP, Ludwig (Hrsg.). Grundlinien der Philosophie des Rechts - Klassiker Auslegen. Berlin: Akademie Verlag GmbH, 1997. p.147-166. 
Hegel's ethical thought. Cambridge: Cambridge University Press, 1990.

. "The emptiness of the moral will”. In: Monist, 72:3, july 1989, p. 454-483.

Recebido em: abril de 2011 Aprovado em: julho de 2011

Email: jthklein@yahoo.com.br 